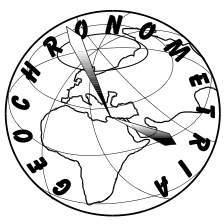

\title{
EMPLOYING MINIMUM AGE MODEL (MAM) AND FINITE MIXTURE MODELING (FMM) FOR OSL AGE DETERMINATION OF TWO IMPORTANT SAMPLES FROM IRA TRENCH OF NORTH TEHRAN FAULT
}

\author{
MORTEZA FATTAHI ${ }^{1}$, MARIAM HEIDARY ${ }^{1}$, MOHAMMAD GHASEMI ${ }^{3}$ \\ ${ }^{I}$ Institute of Geophysics, The University of Tehran, Kargar Shomali, Tehran, Iran \\ ${ }^{2}$ The School of Geography, University of Oxford, south park road, Oxford OX1 3TB \\ ${ }^{3}$ Research Institute for Earth Sciences, Geological Survey of Iran, Azadi Square, Meraj Avenue, P.O. Box 13185-1494, Iran
}

Received 11 July $2015 \quad$ Accepted 2 February 2016

\begin{abstract}
Ira trench site is in a point where, the surface trace of North Tehran Fault (NTF) joins the Mosha Fault (MF) in the north-eastern margin of Tehran and can provide important paleosismological information for Tehran. The Ira trench, were divided into 6 packages (I to VI), described, according to their composition, relative and absolute ages. Package I consists of units 23, 25, 26, 27, 28, 29, 30 and 31. The whole package I mainly belongs to Holocene, and provides essential constraints for the recent paleo-earthquake activity of the EMF and NTF zone. Therefore, finding accurate ages for the units of this package is very important. Three colluvial wedges (units $23,26,28$ ) are present between 20 and $36.5 \mathrm{~m}$ north in package I, which are assigned to 3 episodes of activity on Fault 13. Central age model (CAM) provided OSL ages of $35.0 \pm 6.1,7.3 \pm 1.3,6.4 \pm 0.9$ and $56 \pm 6.5 \mathrm{ka}$ for units 23, 26, 28 and 29 , respectively.

The conflicting ages of $56 \pm 6.5$ and $35.0 \pm 6.1 \mathrm{ka}$ (for units 23 and 29, respectively) as compared to the underlying younger units suggest that these ages are overestimated. MAM provided OSL ages of $13.1 \pm 4.3$ and $3.5 \pm 0.4 \mathrm{ka}$ for units 23 and 29 , respectively. The contribution of the new statistical age model of sample IRA4 to the paleoseismic data is discussed.
\end{abstract}

Keywords: OSL dating, Ira trench, partial bleaching, sediment mixing, active tectonics, Iran.

\section{INTRODUCTIONS}

Tehran where more than 15 million people are living stands at the foothill of the central Alborz mountain, an active mountain range surrounding the southern margin of the South Caspian basin (e.g. Berberian, 1983; Jackson et al., 2002; Allen et al., 2003; Abbasi and Farbod, 2009). The border between the north part of Tehran and southern border of the Alborz mountain is marked by North Teh-

Corresponding author: M. Fattahi e-mail: mfattahi@ut.ac.ir ran Fault (NTF) and Mosha Fault (MF) (Fig. 1). The NTF and MF are located respectively in the northern and northeastern margins of the Tehran metropolis and represent an important seismic hazard for the Iranian capital considering the historical seismicity recorded in the area (e.g. Ambraseys and Melville, 1982; Berberian and Yeats, 1999) and the active tectonics features observed along them (e.g. Berberian et al., 1985; Trifonov et al., 1996; Solaymani et al., 2003; Ritz et al., 2006).

Berberian et al., 1985 attributed the 4 B.C. RayEivanekey earthquake $(\mathrm{Ms} \approx 7.7)$ and the 958 A.D. RayTaleghan earthquake $(\mathrm{Ms} \approx 7.7)$ to the activity of NTF and/or Mosha Fault. Ambraseys and Melville (1982) 
suggested that the earthquake in 1830 A.D. $(\mathrm{M} \approx 7.1)$ was centered very close to the place where the surface expressions of the Eastern Mosha Fault (EMF) and NTF are linked in the Ira area (Fig. 1).

Evidence of predominant active left-lateral strike-slip faulting is found from the eastern Mosha valley to the Tehran City, all along the junction zone between the Mosha and the North Tehran faults and there is kinematic link between the EMF and NTF (Solaymani azad et al., 2011; Ghasemi et al., 2014).

Ghasemi et al. (2014) excavated and studied the Ira trench site in the easternmost part of the NTF, where it joins the MF (the Ira site) (Figs 1 and 2). The trench is located at $51^{\circ} 49^{\prime} 43^{\prime \prime} \mathrm{E}$ and $35^{\circ} 48^{\prime} 23^{\prime \prime} \mathrm{N}$, at an elevation of about $2300 \mathrm{~m}$. They separated thirty three units in the Ira trench, which were divided into 6 packages (I to VI), described, according to their composition, relative and absolute ages.

${ }^{14} \mathrm{C}$ and OSL methods were used to date samples collected from the Ira site (Ghasemi et al., 2014). The whole package I mainly belongs to Holocene (Ghasemi et al., 2014), and provides essential constraints for the recent paleo-earthquake activity of the MF and NTF zone. Therefore, finding accurate ages for all the units of this package is very important. Package I consists of units 23 , $25,26,27,28,29,30$ and 31 which the numbering of units is increasing upwards. IRA8, IRA5, IRA1, IRA4 OSL samples were collected from units 23, 26, 28 and 29, which yield OSL Central Age Model (CAM) ages of $35.0 \pm 6.1,7.3 \pm 1.3,6.4 \pm 0.9$ and $56 \pm 6.5 \mathrm{ka}$, respec-

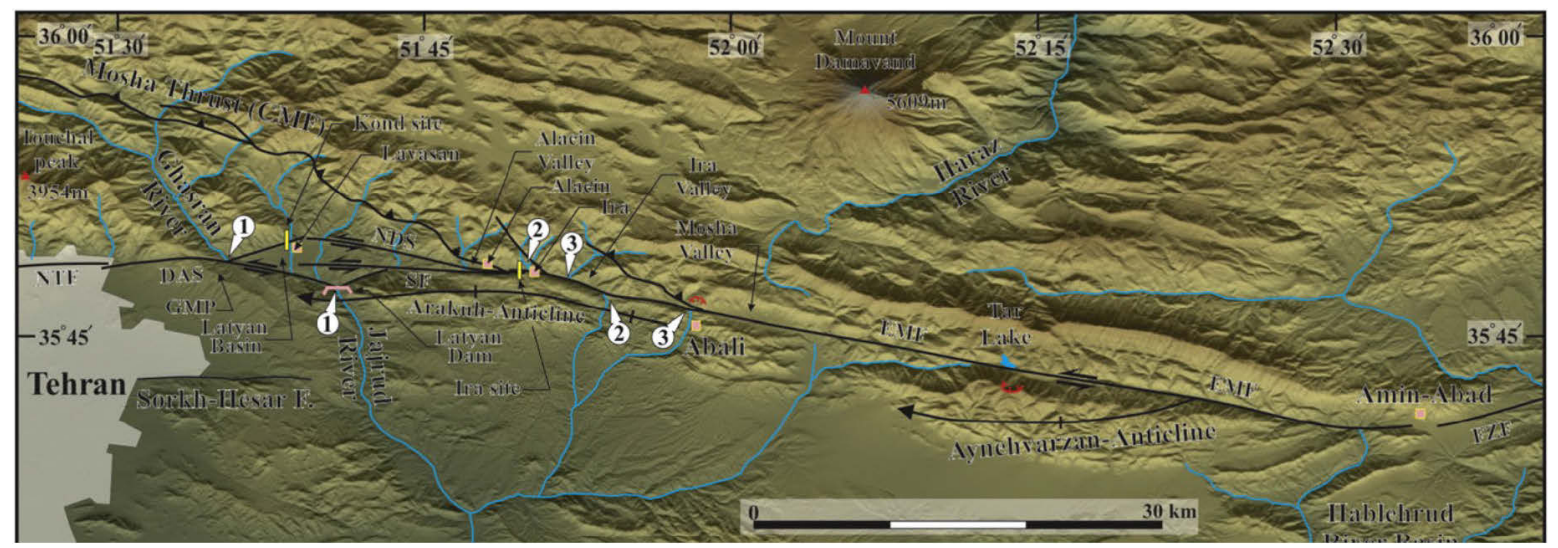

Fig. 1. Regional setting of the EMF and NTF zone showing drainage offsets across the two faults. DAS: Darabad segment of NTF, EMF: Eastern Mosha Fault, FZF: Firuzkuh Fault, GMP: Ghuchak Mountain Pass, NDS: Niknamdeh segment of NTF, NTF: North Tehran Fault zone, SF: Sabu Fault. Squares indicate towns and villages. Breakaway scarp of mass movements are shown by red barbed curves. Note the pull-apart basin in Latyan Basin depression area. Yellowbars showthe two trench sites in this study (not to scale). Arrows and numbers indicate drainage offsets of 9.3, 6.5 and $9.5 \mathrm{~km}$ respectively in 1, 2 and 3. Topography is from SRTM data. (Ghasemi et al., 2014).

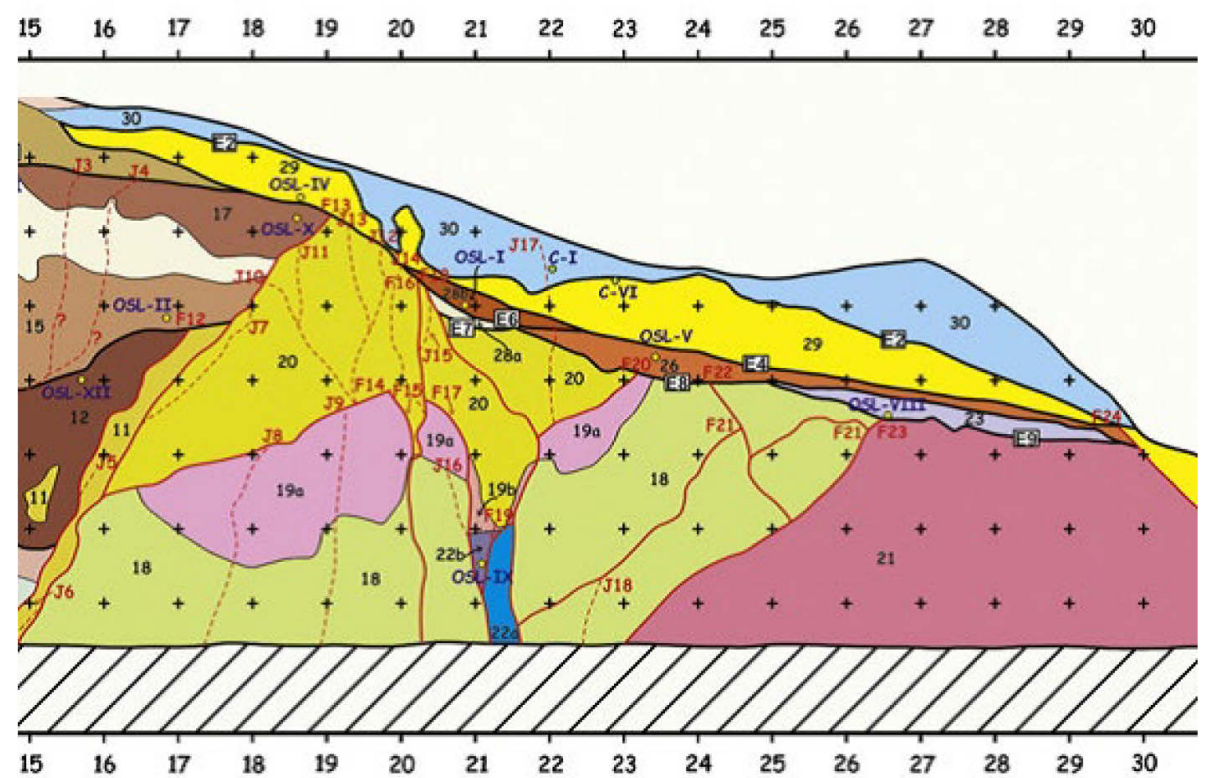

Fig. 2. Part of log of the western trench wall in the Ira site (from Ghasemi et al., 2014). 
tively. The ages of IRA4 and IRA8 are overestimated as compared to the stratigraphy.

The aim of this paper is to find the possible sources of age overestimation for IRA4 and IRA8 and attempts to determine ages close to true ages of these two samples. This paper will first explain the basis of OSL dating and the role of the equivalent dose $\left(D_{e}\right)$. It will later discuss the source errors of $D_{e}$ and explain different methods to overcome this problem. In the end it employs statistical methods to find more reliable ages for samples IRA4 and IRA8. The minimum age for IRA8 is published by Ghasemi et al. (2014) but without scientific details.

\section{OPTICALLY-STIMULATED LUMINESCENCE (OSL) DATING OF THE IRA4 AND IRA8}

Luminescence dating is based on the measurement of two quantities, the total radiation dose the sample has been exposed to since its last exposure to daylight; this is known as the equivalent dose $\left(D_{e}\right)$ and the rate at which it has absorbed energy from the natural environment (the dose rate). The age is obtained by dividing the palaeodose by the dose rate.

$$
\text { Age }(\mathrm{kyr})=\frac{\text { Equivalent dose }(\mathrm{Gy})}{\text { DoseRate }(\mathrm{Gy} / \mathrm{kyr})}
$$

The ability to make replicate measurements of the equivalent dose $\left(D_{e}\right)$ is central to luminescence dating. Single Aliquot Regeneration (SAR) protocol (e.g. Murray and Wintle, 2000) has enabled $D_{e}$ estimates to be obtained from subsamples ('aliquots') composed of a few hundreds of grains or a few tens, and even from single grains (e.g. Roberts et al., 1998, 1999; Jacobs et al., 2003; Olley et al., 2004).

The process of calculating $\mathrm{D}_{\mathrm{e}}$ using the SAR procedure is described in Table 1. It involves measurement of the natural luminescence signal $\left(\mathrm{L}_{\mathrm{N}}\right)$ arising from irradiation in nature, assessing the sensitivity of the aliquot by measuring the luminescence signal $\left(\mathrm{T}_{\mathrm{N}}\right)$ generated by a test dose $\left(\mathrm{D}_{\mathrm{T}}\right)$, and then undertaking a number of cycles

Table 1. Generalized single aliquot regenerated sequence and outline of the steps involved in the SAR method. *Observed $L_{x}$ and $T_{x}$ are derived from the initial IRSL signal (2 s) minus a background estimated from the last part of the stimulation curve. Corrected natural signal $N=L_{0} / T_{0}$; Corrected regenerated signal $R_{x}=L_{x} / T_{x}(x=1-5)$. Note that in step 2, the sample has been heated to the pre-heat temperature using $T L$ and held at that temperature for $10 \mathrm{~s}$.

\begin{tabular}{rll}
\hline Step & Treatment 1 & ${ }^{*}$ Ob \\
\hline 1 & Give dose & - \\
2 & Pre-heat $\left(\operatorname{TL~} 200-300^{\circ} \mathrm{C}\right)$ & - \\
3 & Stimulation $\left(\right.$ at $\left.120^{\circ} \mathrm{C}\right)$ & $\mathrm{L}_{x}$ \\
4 & Give test dose & - \\
5 & Cut-heat $\left(\operatorname{TL} 120-260^{\circ} \mathrm{C}\right)$ & $\overline{\mathrm{T}}_{\mathrm{x}}$ \\
6 & Stimulation $\left(\right.$ at $\left.125^{\circ} \mathrm{C}\right)$ & - \\
7 & Return to 1 & -
\end{tabular}

each of which involves irradiation $\left(\mathrm{D}_{1}, \mathrm{D}_{2}, \mathrm{D}_{3}\right.$, etc. $)$ to regenerate the luminescence signal $\left(\mathrm{L}_{1}, \mathrm{~L}_{2}, \mathrm{~L}_{3}\right.$ etc. $)$, followed by a test of the sensitivity $\left(\mathrm{T}_{1}, \mathrm{~T}_{2}, \mathrm{~T}_{3}\right.$ etc. $)$ using the test dose. The value of $\mathrm{D}_{\mathrm{e}}$ is then found by comparing the ratio $R_{N}\left(=L_{N} / T_{N}\right)$ with an appropriate mathematical equation which fits the resulting ratios $\mathrm{R}_{1}, \mathrm{R}_{2}, \mathrm{R}_{3}$ etc. (obtained from $\mathrm{L}_{1} / \mathrm{T}_{1}, \mathrm{~L}_{2} / \mathrm{T}_{2}, \mathrm{~L}_{3} / \mathrm{T}_{3}$ etc.) to determine the laboratory dose that generates a signal equivalent to that obtained from the natural (Duller, 2007). Using the SAR protocol, each aliquot provides an independent estimate of $\mathrm{D}_{\mathrm{e}}$, and by taking measurements on many separate aliquots the distribution of $\mathrm{D}_{\mathrm{e}}$ within a sample can be assessed (Duller, 2008).

However, to determine a reliable $\mathrm{D}_{\mathrm{e}}$ for a sample, the amount of variation between $D_{e}$ estimates for different grains in an aliquot, or different aliquots that have absorbed the same radiation dose should be investigated.

An understanding of all sources of scatter contributing to such estimates should be well understood or quantified (Galbraith et al., 2005; Stone and Bailey, 2012).

\section{The sources of uncertainty and scatter of $D_{e}$ estimate}

The commonly observed scatter in $\mathrm{D}_{\mathrm{e}}$ distributions of sedimentary samples can be attributed to different sources, referred to by Thomsen et al. (2005) as 'extrinsic' and 'intrinsic' sources of uncertainty. The former sources include: post depositional mixing of grains from adjacent sedimentary layers (e.g. Roberts et al., 1998 and 1999; Bateman et al., 2003, 2007a; Feathers et al., 2006; Jacobs et al., 2006; David et al., 2007) and dosing, poor or heterogeneous bleaching of grains prior to burial (e.g. Olley et al., 2004; Bøtter-Jensen et al., 2000; Duller and Murray, 2000; Duller et al., 2000; Murray and Olley, 2002; Olley et al., 1999, 2004), and dosing, particularly at the micro-scale in the beta-radiation field such as betadose heterogeneity in the natural burial environment (e.g. Olley et al., 1997; Murray and Roberts, 1997; Nathan et al., 2003; Mayya et al., 2006; Jacobs et al., 2008a, 2008b).

'Intrinsic' sources of inconsistency include differences in the OSL signals response from different grains to identical treatments (e.g., Bailey, 2002, 2004) or differing grain-to-grain responses to fixed SAR conditions (e.g. Jacobs et al., 2003); statistical uncertainty due to photon counting and instrument uncertainties and luminescence measurements and then their combination to determine $\mathrm{D}_{\mathrm{e}}$ (e.g. Thomsen et al., 2005; Duller, 2007), such as thermal transfer and photo-transferred recuperation (i.e. transfer of charge from thermally shallow but optically insensitive traps to the deeper trap responsible for the OSL signal, as a result of laboratory heating, optical stimulation, or a combination of the two) (e.g. Aitken and Smith, 1988; Stokes, 1992; Banerjee, 2000). Internal variability leads to the observation of different 'grain behavioural types', seen in luminescence properties such as brightness and dose response characteristics (e.g. Murray and Roberts, 1997; Roberts et al., 1999; Yoshida et 
al., 2000; Jacobs et al., 2003, 2006, 2008b; Stone and Bailey, 2012).

However, an essential assumption of the method is that the luminescence signal from a grain can be reset, or zeroed, by exposure to sufficient daylight. This is a process commonly termed 'bleaching' and occurs in many processes of erosion, transportation or deposition, particularly those that occur sub-aerially. Where all the grains in the sample were exposed to sunlight for sufficient time at deposition to remove any trapped charge, then the sample is fully bleached and all grains would have a $D_{e}$ of zero at deposition, and after some period of burial all the aliquots would give the same value of $D_{e}$ (e.g., aeolian sediments). Where the luminescence signal from some of the grains were not zeroed, grains would have different $D_{e}$ values at the time of deposition; this is termed incomplete or partially bleaching (e.g., alluvial and colluvial sediments) (Duller, 2007).

Sediment mixing by post depositional processes is a dominant source of $\mathrm{D}_{\mathrm{e}}$ variability across a range of sedimentary environments even in quartz-dominated, wellbleached, aeolian, dryland sediments (e.g. Arnold and Roberts, 2009 and references therein). Recognition of sediment mixing in the field is often difficult because the absence of depositional bedding structure is not necessarily indicative of sediment mixing, whilst the presence of sedimentary structure does not necessarily prevent post-depositional disturbance (Bateman et al., 2007a).

The appearance of $D_{e}$ distributions can be affected by the kind of post-depositional processes. The dominant younger (or older) grains intrusion increases positive (negative) skewness. It can increase symmetrically the overall spread of $D_{e}$ values, or create discrete dose populations (including zero-age grains) and multi-modal $\mathrm{D}_{\mathrm{e}}$ distributions. Arnold and Roberts (2009) reported some of the important issues associated with the analysis of mixed $\mathrm{D}_{\mathrm{e}}$ distributions, using simulated $\mathrm{D}_{\mathrm{e}}$ data sets produced with a simple stochastic model.

However, partial bleaching and post-depositional mixing of young/old samples cannot be overcome through optimisation of experimental apparatus and measurement conditions and needs to be addressed via careful statistical analysis of $D_{e}$ distributions and use of appropriate statistical age models.

Several statistical age models have been suggested to obtain estimates from the burial dose associated with only the most fully bleached (and undisturbed) grains in each sample (e.g., Olley et al., 2004; Bailey and Arnold, 2006; Arnold and Roberts, 2009); or of the post-depositionally mixed sediments (e.g. Roberts et al., 2000; Spencer et al., 2003; Sivia et al., 2004).

The most statistically suitable of these are the minimum age model (MAM) of Galbraith and Laslett (1993) for OSL dating of samples that not all the grains have been fully bleached.

The finite mixture model (FMM) of Galbraith and Green (1990) has been used in a number of recent OSL studies of mixed sediments (e.g. Roberts et al., 2000, 2001; Jacobs et al., 2006, 2008b; David et al., 2007; Bateman et al., 2007b).

In this study Mark Bateman spreadsheet was used to calculate the FMM and the program for MAM calculation was provided by Sebastien Huot.

\section{OSL methodology}

Quartz was extracted and cleaned under low-intensity red light at the Sheffield Centre for International Dryland research luminescence laboratory. Carbonates and organics were removed with $\mathrm{HCL}$ and $\mathrm{H}_{2} \mathrm{O}_{2}$. A 45 minutes $\mathrm{HF}$ treatment was followed after heavy minerals separation (S.G. $2.7 \mathrm{gcm}^{-3}$ ). IR stimulation revealed no feldspar contamination. Standard medium single-aliquot dating of the 90-250 $\mu \mathrm{m}$ quartz fractions of samples IRA1, IRA4, IRA5 and IRA8, was performed using standard protocols as outlined in Fattahi et al. (2006).

To test if there were problems from the thermal transfer of charge into the OSL trap as a result of preheating, natural aliquots of sample IRA4 were stimulated at room temperature without any prior preheating and OSL was measured for $100 \mathrm{~s}$. After more than $4 \mathrm{~h}$ delay the OSL was measured again. No significant OSL signal was observed for the second measurement. Then, SAR was applied to measure the $D_{e}$ at different preheat temperatures (expected to be zero in ideal scenario). All subsequently measured apparent values of $D_{e}$ were less than $0.4 \mathrm{~Gy}$ for preheat temperatures from $170^{\circ} \mathrm{C}$ to $300^{\circ} \mathrm{C}$. This is small compared with typical natural $\mathrm{D}_{\mathrm{e}}$ and suggests that the samples do not suffer from significant thermal transfer.

Dose recovery preheat tests (as per Murray and Wintle, 2000, 2003) were carried out and showed that overall effects of sensitivity changes had been properly corrected for and known laboratory doses were recovered by the SAR protocol. The mean ratios of measured to given doses for IRSL were statistically consistent with unity.

Some aliquots were rejected as they were dim or the recycling values were not within $10 \%$ of unity. Some aliquots produced a reasonable OSL signal of which some passed the SAR criteria. These aliquots were chosen for $\mathrm{D}_{\mathrm{e}}$ determination. The CAM provided average ages close to large aliquots for all four samples. The ages of IRA4 and IRA8 were overestimated as compared to the stratigraphy.

The single-aliquot $\mathrm{D}_{\mathrm{e}}$ distributions and the relative profile likelihood graphs are shown in Figs. 3 and 4. A common feature of the $D_{e}$ values of these samples is the widespread distribution of equivalent doses. The spread of single aliquot $D_{e}$ values are because of 'experimental' and 'natural' variations. Experimental errors are reducible but natural variation is inherent. When more than $5 \%$ of $\mathrm{D}_{\mathrm{e}}$ values lie outside $\pm 2 \sigma$ of the central value, the dose distribution is termed over dispersed. Overdispersion (OD) is a quantitative estimate of the amount of spread in the $D_{e}$ data set after allowance has been 
made for measurement uncertainties (Galbraith et al., 1999; Roberts et al., 2000; Galbraith et al., 2005; Galbraith and Roberts, 2012). Many studies have reported up to $20 \%$ over-dispersion among $\mathrm{D}_{\mathrm{e}}$ estimates for single aliquots and individual grains that are known or thought to have been well bleached (e.g., Roberts et al., 2000; Olley et al., 2004; Thomsen et al., 2005; Jacobs et al., 2006; Galbraith and Roberts, 2012).

The $\mathrm{D}_{\mathrm{e}}$ of IRA1 and IRA5 is not as widely spread as IRA4 and IRA 8 . Their OD $(30 \%$ and $25 \%$ for IRA 1 and IRA5, respectively) is low compared to IRA4 (92\%) and IRA8 (57\%).
But what are the sources of the wide spread $D_{e}$ of medium aliquot measured samples? A medium aliquot is still an average of many grains and may hide the wide spread of $D_{e}$ 's of single grains inside medium aliquots. An OD value of $\sim 6 \%$ was obtained for the dose recovery data sets for sample IRA4, so high over-dispersion cannot be due to inherent differences. Therefore, other sources, such as grain-to-grain variations of bleaching and bioturbation may contribute to $\mathrm{D}_{\mathrm{e}}$ scatter for IRA4 and IRA8 samples, with high over-dispersion values ( $92 \%$ and $57 \%$ ).
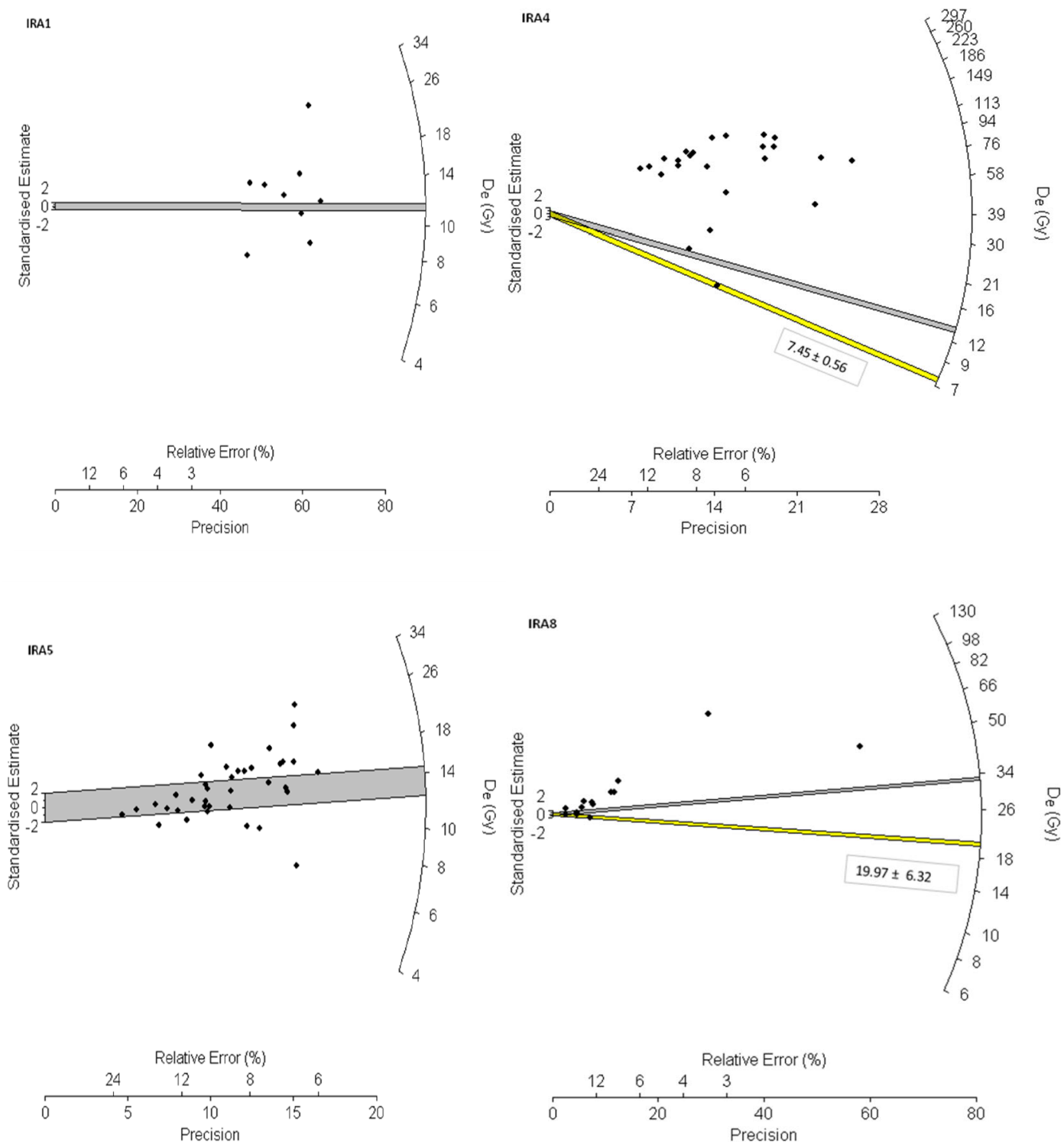

Fig. 3. The De value of IRA samples, representative radial plots of 'mixed and scattered' single aliquot De distributions. The grey bands show values of 2 standard deviations from the $D_{e}$ CAM estimates (Galbraith et al., 1999) for IRA1 and IRA5. The solid yellow lines show the MAM De, and interpreted as representing almost totally bleached grains, which were used for sample De and age determination. The soild gray lines in IRA4 and IRA8 show FMM De. Over dispersion for IRA1, IRA4, IRA5 and IRA8 are 30, 92, 25 and 57, respectively. 

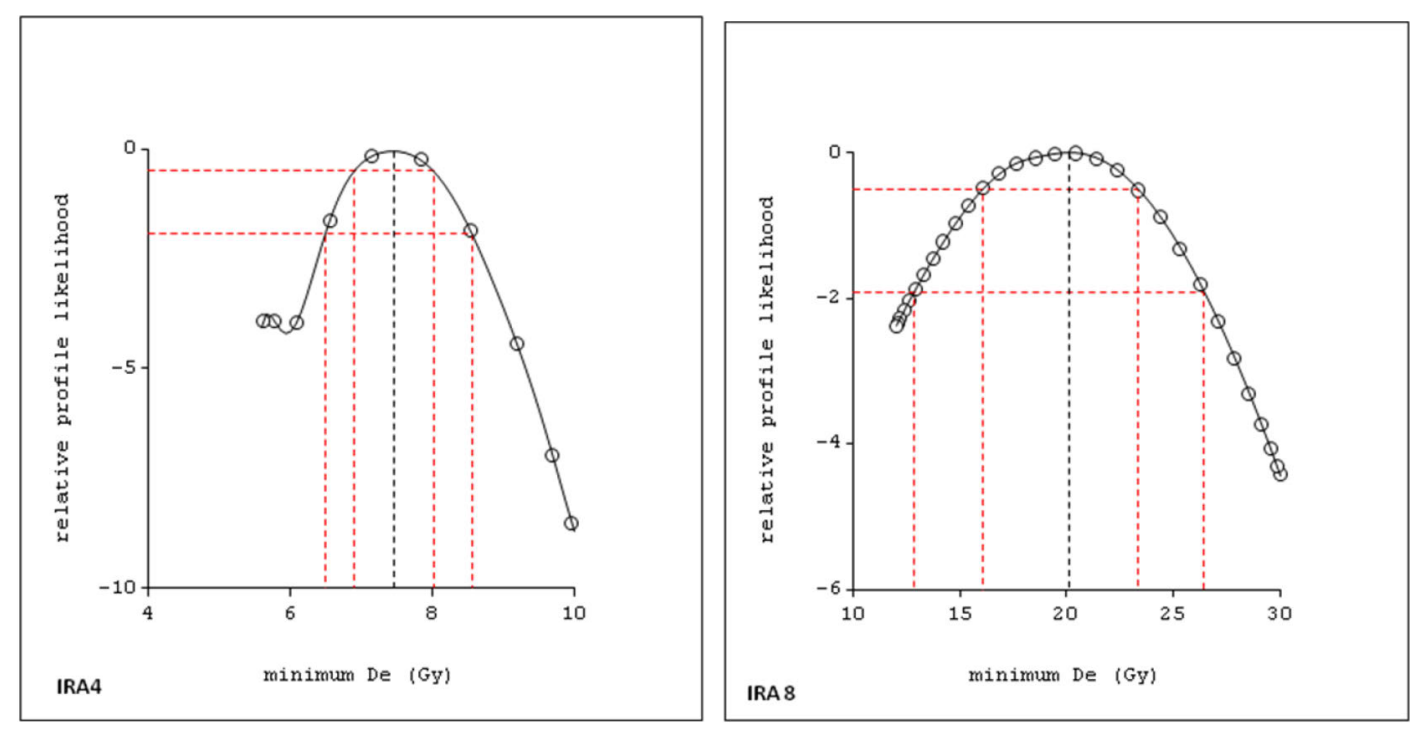

Fig. 4. The relative profile likelihood graphs for quartz single aliquots of IRA4 and IRA8 samples.

\section{Model selection for $D_{\mathrm{e}}$ determination}

Various statistical methods have been developed to isolate grains which represent a true burial dose. For well bleached samples one of the mean calculation methods such as central age model is commonly used. If there are samples that contain a mixture of grains with different bleaching histories, the minimum age model is suitable to determine the minimum age provided by fully bleached grains. The finite mixture model enables one to estimate the number of dose components within a dose distribution and the corresponding $\mathrm{D}_{\mathrm{e}}$ for each component. The lowest component is the youngest cluster of $D_{e} s$.

In order to consider among different statistical approaches which age model is more suitable for our samples, the age model decision process by Arnold et al. (2007) and Bateman et al. (2007a) was used. Specific $\mathrm{D}_{\mathrm{e}}$ distribution characteristics (e.g., over-dispersion, skewness) were taken to identify the appropriate statistical approach.

These age model decision processes suggested the use of CAM for IRA1 and IRA5, and MAM and FMM for IRA4 and IRA8 samples.

The suggestion of age models is consistent with reality. IRA4 and IRA8 samples most likely include grains from different sources and time scales. They are from the environment that the sediments are fluvial, or colluvial. Therefore, grains are likely to be incompletely bleached. MAM is a suitable model to be employed to provide the ages of these samples.

FMM can separate different clusters of Des and suggest an average for each cluster. IRA4 and IRA8 are sampled at the bottom of the units 29 and 23, respectively. Therefore, it is probable that these samples include post-depositional grain through bioturbation from the layer below. For example the age of underlying unit (unit
17) of sample IRA4 was $85.4 \pm 12.1 \mathrm{ka}$, and transformation of grains from this unit to sample IRA4 obviously increase the average age of IRA4. This can be the reason that IRA4 has overestimated the age of unit 29. In this circumstance the age of youngest cluster of FMM can provide the true age of aimed unit.

Therefore, on the basis of the $D_{e}$ scatter, age model decision process and stratigraphy, it has been concluded that, MAM $(13.1 \pm 4.3$ and $3.5 \pm 0.3 \mathrm{ka})$ and the first component of FMM $(21.5 \pm 2.2$ and $6.1 \pm 0.6 \mathrm{ka})$ may give a better indication of the deposition age, rather than CAM $(35 \pm 6.1$ and $58.1 \pm 6.5 \mathrm{ka})$ for IRA 8 and IRA4 samples, respectively. If we combine the age provided by first component of FMM and the age provided by MAM OSL, it will give us 8.8-23.7 and 3.2-6.7 ka for units 23 and 29 , respectively. These ages are more consistent with stratigraphy.

\section{DISCUSSION AND CONCLUSION}

Values used to calculate Annual dose rate and the $D_{e} s$ used to calculate luminescence ages are shown in Table 2 and Table 3, respectively. The MAM age of sample IRA4 $(3.5 \pm 0.3 \mathrm{ka})$ is more compatible with the overall stratigraphic chronology of the exposed units, and is much closer to the radiocarbon age of sample Ira.2008/CIV $(1105 \pm 30 \mathrm{yr}$ BP) collected from the underlying unit 27 (Ghassemi et al., 2014) than CAM age of sample IRA4 $(58.0 \pm 6.5 \mathrm{ka})$. However, the radiocarbon age of sample Ira.2008/C-IV $(1105 \pm 30 \mathrm{yr}$ BP $)$ is still discrepant with this recent MAM age. This apparent discrepancy means that the age of one of these samples or both samples do not represent the age of their units.

If the radiocarbon age of sample Ira.2008/C-IV $(1105 \pm 30 \mathrm{yr}$ BP) does not represent the age of unit 27, it means that this sample may have been emplaced much 
Table 2. Values used to calculate Annual dose rate from IRA trench. Uncertainties are based on the propagation, in quadrature, of errors associated with individual errors for all measured quantities.

\begin{tabular}{llllcccc}
\hline Sample & $\begin{array}{c}\text { Water } \\
(\%)\end{array}$ & $\begin{array}{c}\text { Depth } \\
(\mathbf{m})\end{array}$ & $\begin{array}{c}\mathrm{K} \\
(\%)\end{array}$ & $\begin{array}{c}\mathbf{U} \\
(\mathbf{p p m})\end{array}$ & $\begin{array}{c}\text { Th } \\
(\mathbf{p p m})\end{array}$ & $\begin{array}{c}\text { Cosmic } \\
(\mathbf{G y} / \mathbf{k a})\end{array}$ & $\begin{array}{c}\text { Dose rate } \\
(\mathbf{m G y} / \mathbf{y r})\end{array}$ \\
\hline Ira.I & 5.25 & 1.39 & 1.07 & 1.12 & 5.29 & $0.16 \pm 0.14$ & $1.77 \pm 0.14$ \\
\hline Ira.IV & 9.66 & 0.6 & 1.33 & 1.65 & 6.30 & $0.18 \pm 0.14$ & $2.14 \pm 0.15$ \\
\hline Ira.V & 6.6 & 1.22 & 1.11 & 1.34 & 4.99 & $0.16 \pm 0.14$ & $1.82 \pm 0.14$ \\
\hline Ira.VIII & 8.46 & 2.04 & 0.77 & 1.69 & 4.65 & $0.14 \pm 0.14$ & $1.52 \pm 0.14$ \\
\hline
\end{tabular}

Table 3. $D_{e} s$ used to calculate luminescence ages employing three different statistical methods, Central age model (CAM), Finite mixture modelling (FMM) and Minimum age model (MAM).

\begin{tabular}{|c|c|c|c|c|c|c|c|c|c|c|c|c|}
\hline \multirow{2}{*}{ Sample ID } & \multicolumn{6}{|c|}{$\mathrm{De}$ (Gy) } & \multicolumn{6}{|c|}{ Age (ka) } \\
\hline & CAM & \pm & FMM & \pm & MAM & \pm & CAM & \pm & FMM & \pm & MAM & \pm \\
\hline$\overline{\text { Ira.I }}$ & 11.4 & 1.3 & & & & & 6.4 & 0.9 & & & & \\
\hline Ira.IV & 123.9 & 11.0 & 13.0 & 0.9 & 7.5 & 0.6 & 58.0 & 6.5 & 6.1 & 0.6 & 3.5 & 0.3 \\
\hline Ira.V & 13.3 & 2.0 & & & & & 7.3 & 1.3 & & & & \\
\hline Ira.VIII & 53.3 & 7.9 & 32.7 & 0.9 & 20.0 & 6.3 & 35.0 & 6.1 & 21.5 & 2.2 & 13.1 & 4.3 \\
\hline
\end{tabular}

later than the true burial age of unit 27. This support the idea that unit 27 could be older than the three colluvial wedges (units 23, 26, and 28) and these three colluvial wedges (units 23, 26, and 28) have been formed by three paleoearthquakes applying reverse component on fault F13, and mostly these colluvial wedges are reworked units that have been derived from unit 27. This could also be a plausible explanation of the anomalous young radiocarbon age of sample Ira.2008/C-III $(950 \pm 30 \mathrm{yr}$ BP) compared to the OSL age of overlying unit 25 (sample Ira.2008/OSL-VI: $8.7 \pm 1.6 \mathrm{ka}$, see Tables $\mathbf{1}$ and 2 of Ghassemi et al., 2014). However, if Ira.2008/C-IV $(1105 \pm 30 \mathrm{yr}$ BP) underestimate the age of unit 27, combining the stratigraphic order between units 27 and 29 with the MAM age of OSL sample IRA4 (3.5 $\pm 0.4 \mathrm{ka})$ does not permit Ghassemi et al. (2014) to use the radiocarbon age of sample Ira.2008/C-IV (1105 $\pm 30 \mathrm{yr}$ BP) to identify a possible seismic event at the base of unit 27 , to be associated with the $958 \mathrm{AD}$ Ray-Taleghan event $(\mathrm{M} \approx 7.7)$.

If the MAM age of sample IRA4 $(3.5 \pm 0.4 \mathrm{ka})$ has overestimated the true burial age of unit 29, it has positive effect on the interpretation of Ghassemi et al. (2014) to associate trench seismic events to some historical events (e.g., unit 27, to be associated with the 958 AD Ray-Taleghan). Particularly, it may confirms Ghassemi et al. (2014) interpretation that units 23, 26, 29, and 30 have been cut by faults F24 to F28 in the northern end of the Ira trench, which interpreted as likely of seismic origin associated with the 1830 AD earthquake of DamavandShemiranat $(\mathrm{M} \approx 7.1)$ earthquake, the meizoseismal area of which was centered on the junction between the Mosha and NTF, very close to the Ira site (Fig. 1).

The $\mathrm{D}_{\mathrm{e}}$ overestimation of samples IRA4 and IRA8 can be due to many parameters, including postdepositional mixing and partial bleaching. Both samples are collected from the bottom of their units and the posi- tions of samples are very close to the bottom unit. As a result it is likely that overestimation is due to the inclusion of grains with much higher $\mathrm{D}_{\mathrm{e}}$ either due to upward movement within the profile of older grains (through bioturbation). The signature of post-depositional mixing in principle can be determined at the single-grain scale of analysis, as individual grains that have intruded from older units may be identified as discrete components in a $\mathrm{D}_{\mathrm{e}}$ distribution. We expect by employing single aliquot measurements, the variation in $\mathrm{D}_{\mathrm{e}}$ decrease, but still the minimum cluster of $\mathrm{D}_{\mathrm{e}}$ (first component of FMM) is closer to true age in compare to average $\mathrm{D}_{\mathrm{e}}(\mathrm{CAM})$ for samples that may suffer from partial bleaching or postdepositional mixing.

In order to date partially bleached sediment, it is important to estimate the amount of scatter caused by grainto-grain variability in the natural dose rate. Measurements of such scatter are performed at the single-grain level; by contrast, most OSL dating is performed on multi-grain subsamples, for which grain-to-grain scatter is reduced through averaging. Therefore, the single aliquot MAM age of sample IRA4 $(3.5 \pm 0.4 \mathrm{ka})$ may has overestimated the true burial age of unit 29 .

We tried the conventional method of single grain analysis but due to dim signal, it was not possible to do reliable single grain measurement for our samples. We believe there is no harm to apply MAM and FMM for single aliquot analysis of scattered $D_{e}$. Because only in the absence of $\mathrm{D}_{\mathrm{e}}$ scatter relating to partial bleaching or sediment mixing, CAM provides a representative estimate of the average sample burial dose (Galbraith et al., 1999). But in the cases that we are not sure that partial bleaching or sediment mixing is absent, or there are evidences that they may exist, MAM and FMM can be applied for single aliquot to provide a closer age to true age. 
The 4 BC Ray-Eivanekey earthquake $(\mathrm{Ms} \approx 7.7)$ is suggested to be related to Kahrizak, Garmsar or Parchin active faults. However, it might have triggered either NTF or MF in the Ira site and has produced one of the colluvial wedges or other past earthquake evidence. However, the presented age controls do not permit one to explicitly assign the $4 \mathrm{BC}$ earthquake to one of the recognized past earthquakes in the trench site.

\section{Future direction}

At the multi-grain scale of analysis, however, any heterogeneity in $\mathrm{D}_{\mathrm{e}}$ that individual grains have, may still be masked, as individual $D_{e}$ estimates are obtained from aliquots containing several tens, hundreds of grains. The presence of intrusive grains may therefore become 'covered' in the final $D_{e}$ estimates of individual aliquots that contain a variety of both younger/older intrusive grains and in situ grains. By averaging, as the number of grains that are measured (i.e. the number of grains on each aliquot) increases, the variation in $\mathrm{D}_{\mathrm{e}}$ will decrease (Olley et al., 1999; Wallinga, 2002).

Therefore, due to dim signals of the limited measured aliquots, the best way to find the accurate age for these units is to collect more and bigger samples and try to find shine grains and date them using single grains or very small aliquots.

\section{ACKNOWLEDGEMENTS}

We would like to thank Saeid H. Tabatabaei, Mehdi Ahmadi, Angela Landgraf, and Paolo Ballato for helping us for site selection, logging and sample collection.

Mark Bateman and Sebastien Huot are thanked for providing the FMM spreadsheet and Excel macros for MAM program, respectively. Two anonymous reviewers are thanked for providing constructive insightful comments and correcting general English which upgraded the manuscript significantly.

\section{REFERENCES}

Abbassi MR and Farbod Y, 2009. Faulting and folding in Quaternary deposits of Tehran's piedmont (Iran). Journal of Asian Earth Science 34: 522-531, DOI 10.1016/j.jseaes.2008.08.001.

Aitken MJ and Smith BW, 1988. Optical dating: recuperation after bleaching. Quaternary Science Reviews 7: 387-393, DOI 10.1016/0277-3791(88)90034-0.

Allen MB, Vincent SJ, Alsop I, Ismail-zadeh A and Flecker R, 2003. Late Cenozoic deformation in the South Caspian region: effects of a rigid basement block within a collision zone. Tectonophysics 366: 223-239, DOI 10.1016/S0040-1951(03)00098-2.

Ambraseys NN and Melville CP, 1982. A History of Persian Earthquakes. Cambridge University Press, London (219 pp.).

Arnold LJ and Roberts RG, 2009. Stochastic modelling of multi-grain equivalent dose (De) distributions: Implications for OSL dating of sediment mixtures. Quaternary Geochronology 4(3): 204-230, DOI 10.1016/j.quageo.2008.12.001.
Arnold LJ, Bailey RM and Tucker GE, 2007. Statistical treatment of fluvial dose distributions from southern Colorado arroyo deposits. Quaternary Geochronology 2: 162-167, DOI 10.1016/j.quageo.2006.05.003.

Bailey RM, 2002. Simulations of variability in the luminescence characteristics of natural quartz and its implications for estimates of absorbed dose. Radiation Protection Dosimetry 100(1-4): 33-38.

Bailey RM, 2004. Paper I e simulation of dose absorption in quartz over geological timescales and its implications for the precision and accuracy of optical dating. Radiation Measurements 38: 299-310, DOI 10.1016/j.radmeas.2003.09.005.

Bailey RM and Arnold LJ, 2006. Statistical modelling of single grain quartz De distributions and an assessment of procedures for estimating burial dose. Quaternary Science Reviews 25: 2475-2502, DOI 10.1016/j.quascirev.2005.09.012.

Banerjee D, 2000. Thermal transfer and recuperation in quartz OSL and their consequences regarding optical dating procedure. In: Murthy KVR et al., eds., Luminescence and its applications. Luminescence Society of India C 1/2000: 86-93.

Bateman MD, Frederick CD, Jaiswal MK and Singhvi AK, 2003. Investigations into the potential effects of pedoturbation on luminescence dating. Quaternary Science Reviews 22: 1169-1176, DOI 10.1016/S0277-3791(03)00019-2.

Bateman MD, Boulter CH, Carr AS, Frederick CD, Peter D and Wilder M, 2007. Detecting Post-depositional sediment disturbance in sandy deposits using optical luminescence. Quaternary Geochronology 2(1-4): 57-64, DOI 10.1016/j.quageo.2006.05.004.

Bateman MD, Boulter CH, Carr AS, Frederick CD, Peter D and Wilder M, 2007b. Preserving the palaeoenvironmental record in drylands: bioturbation and its significance for luminescence-derived chronologies. Sedimentary Geology 195: 5-19, DOI 10.1016/j.sedgeo.2006.07.003.

Berberian M, 1983. The southern Caspian: a compressional depression floored by atrapped, modified oceanic crust. Canadian Journal of Earth Sciences 20: 163-183, DOI 10.1139/e83-015.

Berberian M, Qorashi M, Arzhang-ravesh B and Mohajer-Ashjai A, 1985. Recent tectonics, seismotectonics and earthquake-fault hazard investigation in the Greater Tehran region: contribution to the seismotectonics of Iran, part V. Geological Survey of Iran, Report No. 56 ([in Persian], 316 pp.).

Berberian M and Yeats RS, 1999. Patterns of historical earthquake rupture in the Iranian plateau. Bulletin of the Seismological Society of America 89: 120-139.

Bøtter-Jensen L, Solongo S, Murray AS, Banerjee D and Jungner H, 2000. Using the OSL single-aliquot regenerative-dose protocol with quartz extracted from building materials in retrospective dosimetry. Radiation Measurements 32: 841-845, DOI 10.1016/S1350-4487(99)00278-4.

Jackson J, Priestley K, Allen M and Berberian M, 2002. Active tectonics of the South Caspian Basin. Geophysical Journal International 148: 214-245, DOI 10.1046/j.1365-246X.2002.01588.x.

David B, Roberts RG, Magee J, Mialanes J, Turney C, Bird M, White C, Fifels LK and Tibby J, 2007. Sediment mixing at Nonda Rock: investigations of stratigraphic integrity at an early archaeological site in northern Australia and implications for the human colonisation of the continent. Journal of Quaternary Science 22: 449-479, DOI 10.1002/jqs. 1136.

Duller GAT, 2007. Assessing the error on equivalent dose estimates derived from single aliquot regenerative dose measurements. $\mathrm{An}$ cient TL 25: 15-24.

Duller GAT, 2008. Single-grain optical dating of Quaternary sediments: why aliquot size matters in luminescence dating. Boreas 37(4): 589-612, DOI 10.1111/j.1502-3885.2008.00051.x.

Duller GAT and Murray AS, 2000. Luminescence dating of sediments using individual mineral grains. Geologos 5: 87-106.

Duller GAT, Bøtter-Jensen L and Murray AS, 2000. Optical dating of single sandsized grains of quartz: sources of variability. Radiation Measurements 32: 453-457, DOI 10.1016/S1350-4487(00)00055-X. 
Fattahi M, Walker R, Hollingsworth J, Bahroudi A, Talebian M, Armitage S and Stokes S, 2006. Holocene slip-rate on the Sabzevar thrust fault, NE Iran, determined using Optically-stimulated Luminescence (OSL). Earth and Planetary Science Letters 245: 673-684, DOI 10.1016/j.eps1.2006.03.027.

Feathers JK, Holliday VT and Meltzer DJ, 2006. Optically stimulated luminescence dating of Southern High Plains archaeological sites. Journal of Archaeological Science 33: 1651-1665, DOI 10.1016/j.jas.2006.02.013.

Galbraith RF and Green PF, 1990. Estimating the component ages in a finite mixture. Nuclear Tracks and Radiation Measurements 17(3): 197-206, DOI 10.1016/1359-0189(90)90035-V.

Galbraith RF and Laslett GM, 1993. Statistical models for mixed fission track ages. Nuclear Tracks and Radiation Measurements 21: 459470, DOI 10.1016/1359-0189(93)90185-C.

Galbraith RF, Roberts RG, Laslett GM, Yoshida H and Olley JM, 1999. Optical dating of single and multiple grains of quartz from Jinmium rock shelter, northern Australia: Part I, experimental design and statistical models. Archaeometry 41: 339-364, DOI 10.1111/j.1475-4754.1999.tb00987.x.

Galbraith RF, Roberts RG and Yoshida H, 2005. Error variation in OSL palaeodose estimates from single aliquots of quartz: a factorial experiment. Radiation Measurements 39: 289-307, DOI 10.1016/j.radmeas.2004.03.023.

Galbraith RF and Roberts RG, 2012. Statistical aspects of equivalent dose and error calculation and display in OSL dating: An overview and some recommendations. Quaternary Geochronology 11: 1-27, DOI 10.1016/j.quageo.2012.04.020.

Ghassemi M, Fattahi M, Landgraf A, Ahmadai M, Ballato P and Tabatabaei S, 2014. Kinematic links between the Eastern Mosha Fault and the North Tehran Fault, Alborz range, northern Iran. Tectonophysics 622: 81-95, DOI 10.1016/j.tecto.2014.03.007.

Jacobs Z, Duller GAT and Wintle AG, 2003. Optical dating of dune sands from Blombos Cave, South Africa: II - single grain data. Journal of Human Evolution 44: 613-623, DOI 10.1016/S00472484(03)00049-6.

Jacobs Z, Duller GAT and Wintle AG, 2006. Interpretation of single grain De distributions and calculation of De. Radiation Measurements 41: 264-277, DOI 10.1016/j.radmeas.2005.07.027.

Jacobs Z, Wintle AG, Duller GAT, Roberts RG and Wadley L, 2008a. New ages for the post-Howiesons Poort, late and final Middle Stone Age at Sibudu, South Africa. Journal of Archaeological Science 35: 1790-1807, DOI 10.1016/j.jas.2007.11.028.

Jacobs Z, Wintle AG, Roberts RG and Duller GAT, 2008b. Equivalent dose distributions from single grains of quartz at Sibudu, South Africa: context, causes and consequences for optical dating of archaeological deposits. Journal of Archaeological Science 35: 1808-1820, DOI 10.1016/j.jas.2007.11.027.

Mayya YS, Morthekai P, Murari MK and Singhvi AK, 2006. Towards quantifying beta microdosimetric effects in single-grain quartz dose distribution. Radiation Measurements 41: 1032-1039, DOI 10.1016/j.radmeas.2006.08.004.

Murray AS and Roberts RG, 1997. Determining the burial time of single grains of quartz using optically stimulated luminescence. Earth and Planetary Science Letters 152: 163-180, DOI 10.1016/S0012-821X(97)00150-7.

Murray AS and Wintle AG, 2003. The single aliquot regenerative dose protocol: 651 potential for improvements in reliability. Radiation Measurements 37: 377-381, DOI 10.1016/S1350-4487(03)00053-2.

Murray AS and Wintle AG, 2000. Luminescence dating of quartz using an improved single aliquot regenerative-dose protocol. Radiation Measurements 32: 57-73, DOI 10.1016/S1350-4487(99)00253-X.

Murray AS and Olley JM, 2002. Precision and accuracy in the optically stimulated luminescence dating of sedimentary quartz: a status review. Geochronometria 21: 1-16.

Nathan RP, Thomas PJ, Jain M, Murray AS and Rhodes EJ, 2003. Environmental dose rate heterogeneity of beta radiation and its implications for luminescence dating: Monte Carlo modelling and experimental validation. Radiation Measurements 37: 305-313, DOI 10.1016/S1350-4487(03)00008-8.

Olley JM, Roberts RG and Murray AS, 1997. Disequilibria in the uranium decay series in sedimentary deposits at Allen's Cave, Nullarbor Plain, Australia: implications for dose rate determinations. Radiation Measurements 27: 433-443, DOI 10.1016/S13504487(96)00114-X.

Olley JM, Caitcheon GG and Roberts RG, 1999. Origin of dose distributions in fluvial sediments, and the prospect of dating single grains from fluvial deposits using optically stimulated luminescence. Radiation Measurements 30: 207-217, DOI 10.1016/S1350-4487(99)00040-2.

Olley JM, Pietsch T and Roberts RG, 2004. Optical dating of Holocene sediments from a variety of geomorphic settings using single grains of quartz. Geomorphology 60: 337-358, DOI 10.1016/j.geomorph.2003.09.020.

Ritz J-F, Nazari H, Ghassemi A, Salamati R, Shafei A, Solaymani S and Vernant P, 2006. Active transtension inside Central Alborz: a new insight into the northern Iran- southern Caspian geodynamics. Geology 34(6): 477-480, DOI 10.1130/G22319.1.

Roberts R, Bird M, Olley J, Galbraith R, Lawson E, Laslett G, Yoshida H, Jones R, Fullager R, Jacobsen G and Hua Q, 1998. Optical and radiocarbon dating at Jinmium rock shelter in northern Australia. Nature 393: 358-362, DOI 10.1038/30718.

Roberts RG, Galbraith RF, Olley JM, Yoshida H and Laslett GM, 1999. Optical dating of single and multiple grains of quartz from Jinmium rock shelter, northern Australia: part II, results and implications. Archaeometry 41: 365-395, DOI 10.1111/j.14754754.1999.tb00988.x.

Roberts RG, Galbraith RF, Yoshida H, Laslett GM and Olley JM, 2000. Distinguishing dose populations in sediment mixtures: a test of single-grain optical dating procedures using mixtures of laboratory-dosed quartz. Radiation Measurements 32: 459-465, DOI 10.1016/S1350-4487(00)00104-9.

Roberts RG, Flannery TF, Ayliffe LK, Yoshida H, Olley JM, Prideaux GJ, Laslett GM, Baynes A, Smith MA, Jones R and Smith BL, 2001. New ages for the last Australian megafauna: continent-wide extinction about 46,000 years ago. Science 292: 1888-1892, DOI 10.1126/science. 1060264 .

Sivia DS, Burbidge C, Roberts RG and Bailey RM, 2004. A Bayesian approach to the evaluation of equivalent doses in sediment mixtures for luminescence dating. In: Fischer, R., Preuss, R., von Toussaint, U. (Eds.), Bayesian Inference and Maximum Entropy Methods in Science and Engineering: 24th International Workshop on Bayesian Inference and Maximum Entropy Methods in Science and Engineering. American Institute of Physics Conference Proceedings 735 , pp. 305-311.

Solaymani Sh, Feghhi Kh, Shabanian E, Abbassi MR and Ritz JF, 2003. Preliminary Paleoseismological Studies on the Mosha Fault at Mosha Valley. International Institute of Earthquake Engineering and Seismology. 89 pp. (in Persian).

Solaymani Azad S, Ritz J-F and Abbassi MR, 2011. Left-lateral active deformation along the Mosha-North Tehran fault system (Iran): morphotectonics and paleoseismological investigations. Tectonophysics 497, 1-14, DOI 10.1016/j.tecto.2010.09.013.

Spencer JQ, Sanderson DCW, Deckers K, Sommerville AA, 2003 Assessing mixed dose distributions in young sediments identified using small aliquots and a simple two-step SAR procedure: the Fstatistic as a diagnostic tool. Radiation Measurements 37: 425431, DOI 10.1016/S1350-4887(03)00064-7.

Stokes S, 1992. Optical dating of young (modern) sediments using quartz: results from a selection of depositional environments. Quaternary Science Reviews 11: 153-159, DOI 10.1016/02773791(92)90057-F.

Stone AEC and Bailey RM, 2012. The effect of single grain luminescence characteristics on single aliquot equivalent dose estimates. Quaternary Geochronology 11: 68-78, DOI 10.1016/j.quageo.2012.03.014 
Thomsen KJ, Murray AS and Bøtter-Jensen L, 2005. Sources of variability in OSL dose measurements using single grains of quartz. Radiation Measurements 39 47-61,

DOI 10.1016/j.radmeas.2004.01.039.

Trifonov VG, Hessami KT and Jamali F, 1996. West-Trending Oblique Sinitral-Reverse Fault system in Northern Iran: IIEES Special Publication 75. Tehran, Iran.
Yoshida H, Roberts RG, Olley JM, Laslett GM and Galbraith RF, 2000. Extending the age range of optical dating using single 'supergrains' of quartz. Radiation Measurements 32: 439-446, DOI 10.1016/S1350-4487(99)00287-5.

Wallinga J, Murray AS and Bøtter-Jensen L, 2002. Measurement of the dose in quartz in the presence of feldspar contamination. Radiation Protection Dosimetry 101: 367-370. 